\title{
EFFERENT CONNEXIONS OF THE HUMAN PREFRONTAL REGION WITH REFERENCE TO FRONTO-HYPOTHALAMIC PATHWAYS
}

\author{
BY \\ E. BECK, A. MEYER*, and J. LE BEAU \\ From the Department of Neuropathology, Institute of Psychiatry, Maudsley Hospital, London
}

This paper was initiated by the necropsy of a case in which an ablation (topectomy) of the frontal pole, more or less confined to area $10 / \mathrm{FE}$, had been carried out by one of us (J. Le B.). Such cases with circumscribed lesions give an almost unique opportunity of studying the connexions of certain areas with lower centres which, in the human brain at least, are by no means well established. Previous reports on the afferent thalamic connexions of area 10/FE have been conflicting (Walker, 1940a and b ; Freeman and Watts, 1947 ; Meyer, Beck, and McLardy, 1947 ; McLardy, 1950). Its efferent systems have recently been investigated by one of us (Beck, 1950) with particular reference to the prefronto-pontine system. The present case gives a welcome opportunity of checking previous results and clarifying controversial points. It will be seen that it also throws some new light on frontohypothalamic connexions which have received special attention lately (Le Gros Clark and Meyer, 1950) and which are of particular interest to the psychiatrist searching for the rationale of neurosurgical operations in mental patients.

For comparison of the anatomical data one case of rostral leucotomy, as practised by Mr. McKissock in this country, has been included. This operation

- aims at undercutting areas 9/FDm and 10/FE, although, as will be seen later, a slightly wider region has been isolated in this particular case. The brain was specially suitable for comparison, since the age of the patient and the survival period were almost identical.

In cases with short survival the best method for studying secondary degeneration is silver impregnation. In this investigation as well as in previous ones from this laboratory, Glees' ammoniacal silver method (Glees, 1946) has proved of great value. The difficulties encountered in the evaluation of

* These cases were demonstrated at the meeting of the Physiological Society held on December 16,1950, at the Middlesex Hospital, London. silver preparations have been sufficiently stressed by a number of authors including Le Gros Clark and Meyer (1947), Meyer (1949), and Nauta (1950). The material presented in this paper impregnated well. Negative findings in a given area could safely be regarded as proof of the absence of any fibre connexion with the ablated or isolated region; on the other hand only an accumulation of grossly degenerated fibres and/or terminals was taken to signify the existence of such a connexion.

The primary lesions were evaluated microscopically; the Brodmann numerals* inserted in the diagrams Figs. 2 and 4, correspond to the actual cytoarchitectonic structure as observed in the sections. Since in both cases the lesions were fairly symmetrically placed in the two hemispheres only one side has been studied; the left hemisphere in Case 1, the right hemisphere in Case 2.

\section{Observations on Case Material}

Case 1.-M.O. was a woman, aged 67, who died 11 days after bilateral ablation of area 10/FE for intractable pain following trigeminal herpes zoster. The patient suddenly collapsed half an hour after a small routine blood transfusion and died.

Macroscopic Description.-The general appearance of the brain was normal (weight $1,270 \mathrm{~g}$.) ; the arteries of the base showed no atheroma. Removal of the cerebellum and bisection of the cerebral hemispheres, however, revealed a circumscribed softening in the posterior parts of the right gyri hippocampus and fusiformis, and in those portions of the lingual gyrus and the cuneus which include striate and parastriate cortex. Histological investigation showed that there were also circumscribed lesions in the lateral thalamic nucleus and lateral geniculate body.

Ablation of the frontal poles had been carried out almost symmetrically to a depth of approximately $2.5 \mathrm{~cm}$. on the left and $2 \mathrm{~cm}$. on the right side (Fig. 1).

* The terminology used in the text is that of Brodmann and Economo, and Koskinas and, for the orbital surface, that suggested by one of us (Beck, 1949). From the diagrams Economo and Koskinas' symbols have been omitted. 


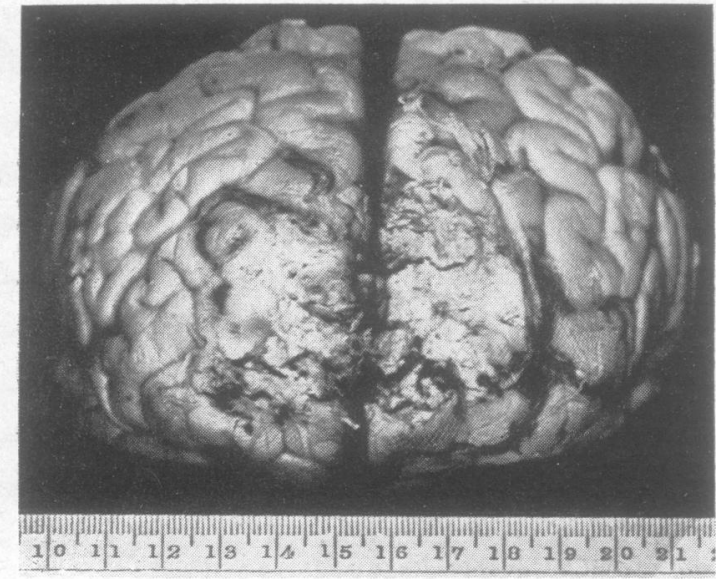

FIG. 1.-Macroscopic appearance of the ablated frontal poles in Case 1.
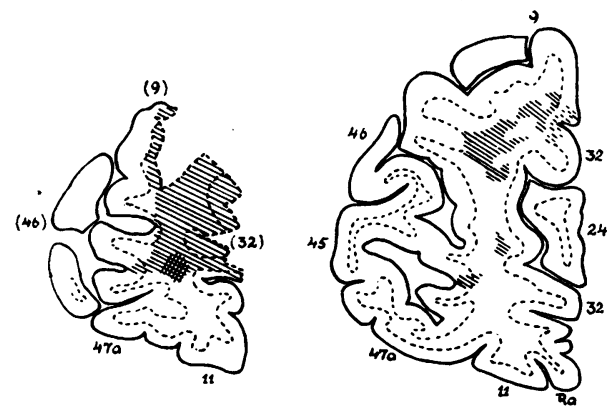

Fig. 2.*-Diagram of the posterior extremity of the left lesion in coronal sections (Case 1). The gaping sulci on the left of each drawing were filled by subarachnoid haemorrhage.

Apart from complete destruction of area 10/FE the lesion encroached upon anterior portions of area $9 / \mathrm{FDm}$ dorsally and areas 32/FDL and 24/LA medially. The orbital surface, areas 47 anterior, 11 and recta anterior, was not involved. A coronal cut at the level of the posterior extremity of the lesion (Fig. 2) revealed a small subarachnoid haemorrhage in the depth of the left inferior frontal sulcus, the right hemisphere being intact at this level. There was no evidence of any further damage at this or more posterior levels of the frontal lobes, and apart from the softening in the right temporo-occipital region, the rest of the brain appeared normal.

Microscopic Description: Left Hemisphere.-The full length of the hypothalamus was investigated at nine representative coronal levels. There was no significant evidence of fibre or terminal degeneration in any of its nuclei.

The thalamus was investigated at seven representative levels, from the most anterior extremity of the anterior nucleus to the level of the posterior end of the dorsomedial nucleus. A small focus of terminal degeneration was found in the anterior portion of the dorso-medial nucleus adjacent to the pars magnocellularis (Fig. 3). Within this focus degeneration was severe (Fig. 6). No further degeneration was seen in the rest of the dorsomedial nucleus or in any of the other thalamic nuclei.

The prefronto-pontine tract as defined by Beck (1950) was studied at three representative coronal levels; namely in the ventral portion of the posterior limb of the internal capsule adjacent to the nucleus ventralis lateralis, at its descent into the cerebral peduncle, and at its termination in the small medial fascicles of the pons. It appeared perfectly normal at each level (Figs. 9 and 11). In the pons many normal terminals could be seen.

The frontal cortex, immediately posterior to the lesion, showed terminal degeneration in its whole circumference, most marked laterally. Degenerated pericellular plexuses were seen in all layers, being slightly more numerous in the deeper layers. Degenerated terminals most frequently appeared as solid, bulb-like structures and only isolated rings could be seen. Many of the radial bundles showed a number of grossly degenerated fibres. In blocks taken $1 \mathrm{~cm}$. and $2.5 \mathrm{~cm}$. still further posteriorly, from areas $8 / F C$ and $6 / F B$ respectively, degeneration was no longer apparent. Degenerated fibres were seen crossing in the genu corporis callosi.

Slight degeneration occurred in the medial portion

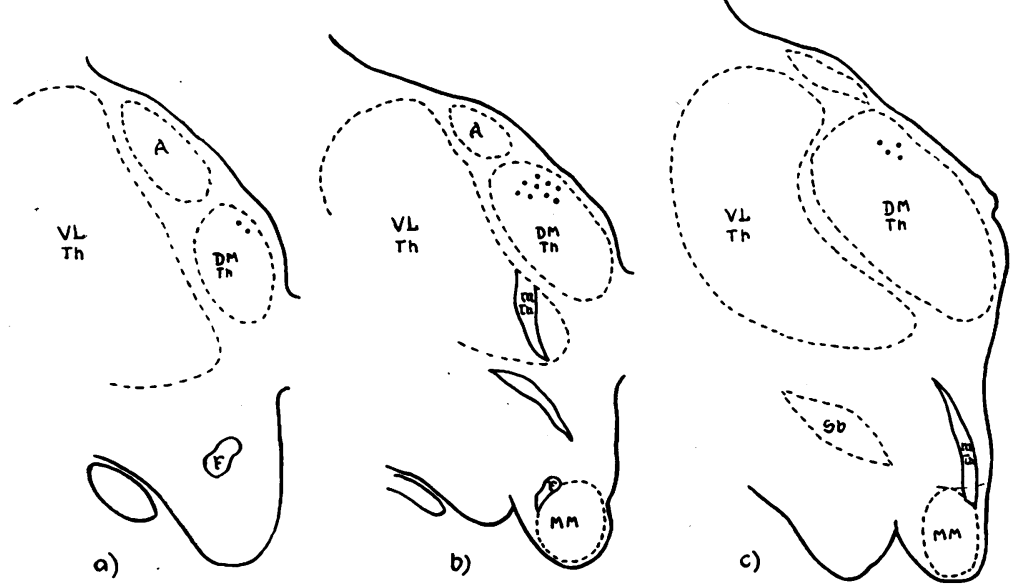

Fig. 3.-Diagram indicating the secondary degeneration in the dorso-medial nucleus of the left thalamus of Case 1 (dotted area).
The following abbreviations are used in the text figures :

$\mathbf{A}=$ nucleus anterior thalami; $\quad$ Arc $=$ nucleus periventricularis arcuatus; $\mathbf{D M}=$ nucleus dorsomedialis hypothalami; DM Th = nucleus dorsomedialis thalami; $\quad F=$ fornix $; \quad F L=$ fasciculus lenticularis; $\quad F T h=$ fasciculus thalamicus; $\quad I C=$ capsula interna ; $\mathbf{L} \mathbf{H}=$ nucleus lateralis hypothalami ; $\mathbf{M M}=$ nucleus mamillaris medialis ; MTh = tractus mamillo-thalamicus ; O Tr = tractus opticus ; $\mathbf{P}=$ pedunculus cerebrale $; \mathbf{P A}=$ nucleus paraventricularis ; $\mathbf{P H}=$ area posterior hypothalami ; $\mathbf{R a}=$ area recta anterior; $\mathbf{S b}=$ corpus subthalamicum; $\mathrm{SO}=$ nucleus supraopticus; $\mathbf{T b}=$ nucelus tuberis ; VL $\mathbf{T h}=$ nucleus ventralis lateralis thalami; $\mathbf{V M}=$ nucleus ventralis medialis hypothalami; $\quad \mathbf{Z}=$ zona incerta $; \quad$ III = ventriculus tertius.

* In this and Fig. 4 the extent of the surgical lesion has been indicated by cross and single hatching according to its severity. 

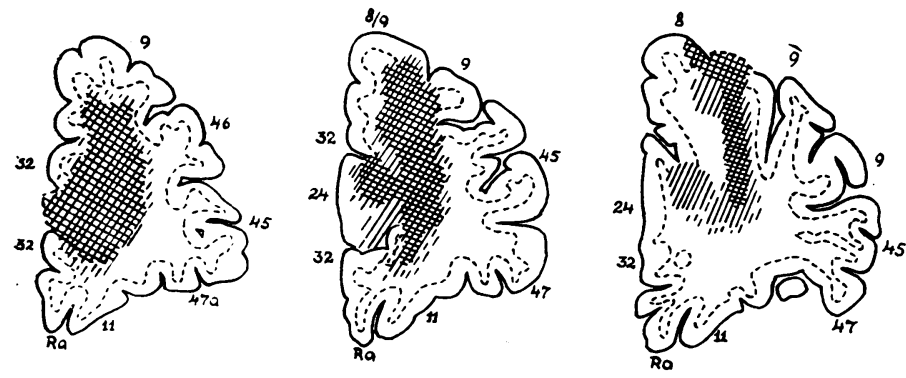

sphere, but completely sparing the lateral half. It terminated within the frontal pole in a similar medial position. Fibres from areas recta anterior, 11, 32/FDL, 24/LA, 10/FE, 9/FDm, and most anterior 8/FC were involved, while those from areas 47 anterior, $46 /$ FD $\Delta$ and $45 / F D \tau$ were probably spared.

Microscopic Description: Right Hemisphere.-The whole length of the hypothalamus was investigated at seven representative coronal levels (Fig. 5). In contrast

of the superior longitudinal fasciculus and in the fasciculus cinguli. The latter, however, was probs bly directly involved in the lesion at its pregenual portion. The uncinate and subcallosal fasciculi showed no significant degeneration.

Other regions investigated included the subthalamic nucleus, zona incerta, Forel's fields $\mathrm{H} 1$ and $\mathrm{H} 2$, and the substantia nigra, all of which were normal.

The lesion in the right temporo-occipital region presented the appearance of a fairly recent ischaemic necrosis (probably less than one week old), with degenerated nerve cells, occasionally showing ischaemic change, marked endothelial and early astrocytic proliferation. It was strictly confined to an area supplied by the posterior cerebral artery although, despite a search, no thrombosis could be found in this artery or any of its branches. It may, however, have been missed. In this position the lesion could not have contributed to any of the secondary degeneration in the left hemisphere described above.

All arteries of this brain, particularly those of medium and small calibre, showed distinct adventitial fibrosis. There was no appreciable excess of lipofuscin in the nerve cells nor were senile plaques or Alzheimer's neurofibril change found.

Case 2.-E.L. was a woman, aged 68, who died from asphyxia, following inhalation of vomitus, 10 days after bilateral rostral leucotomy for involutional depression.

Macroscopic Description.-The general appearance of the brain was normal (weight 1,390 g.). There was no obvious atrophy and no atheroma of the arteries of the base.

The leucotome entry marks were visible in the dorsal aspect of area $9 / \mathrm{FDm}$, the left one lying about $4 \mathrm{~mm}$. from the midline, the right one about $15 \mathrm{~mm}$. On coronal section the lesion (Fig. 4) in the right hemisphere was seen to terminate at the level of the pregenual gyrus cinguli. Here it occupied the dorso-medial segment of the hemisphere sparing the orbital region at this level. One half centimetre further anteriorly, however, the lesion extended into the medial orbital region, thus occupying the entire medial half of the hemi-

* In this and Fig. 2 the extent of the surgical lesion has been indicated by cross and single hatching according to its severity.
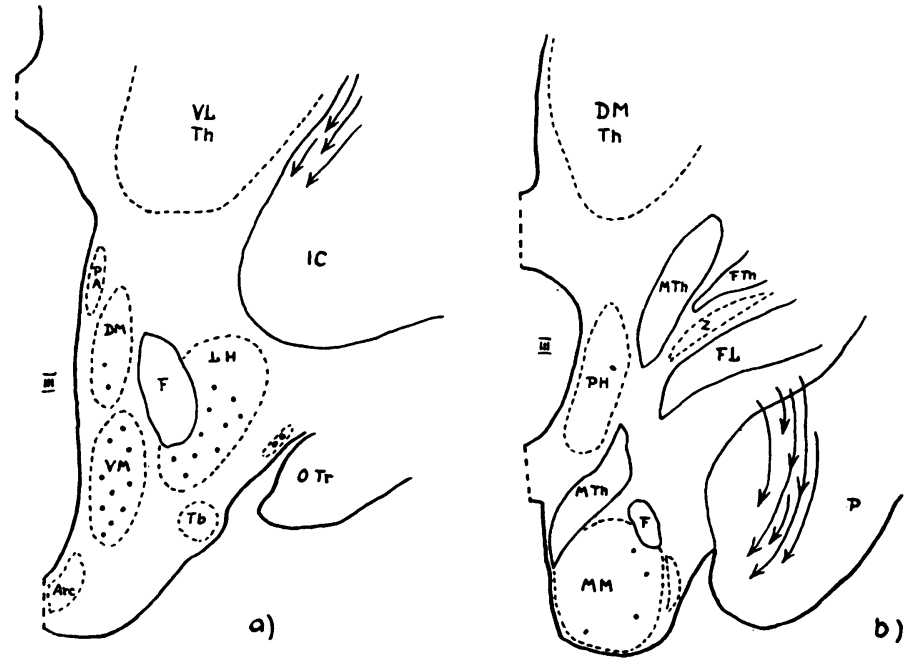

FIG. 5.-Diagram showing the secondary degeneration (Case 2) in the right hypothalamus (dotted areas.)

The course of the degenerated prefronto-pontine tract is indicated by arrows. (Compare Beck, 1950, Fig. 13, for its caudal course.) to Case 1 considerable fibre and terminal degeneration was observed in the ventro-medial and lateral hypothalamic nuclei. Furthermore there was a degeneration in the dorso-medial hypothalamic and 8) and in the medial mammillary nucleus (Figs. ? the region of the medial forebrain bundle and diagonal band to the level of the anterior commissure. A few degenerating fibres were present in the putaminoate junction below the internal capsule. There nor in the periventricular arcuate nucleus. The remaining hypothalamic nuclei also appeared normal.

The thalamus was investigated at five representative levels from the anterior tip of the anterior nucleus to the of the centre median nucleus. In comparison with fibre and terminal degeneration in the anterior half of the dorso-medial nucleus. The nuclei ventralis anterior and lateralis were normal, as were the fine-fibred fascicles traversing them on their way to the dorso-medial nucleus (Meyer, 1949). No degeneration was seen in several evels of the anterior thalamic nucleus.

The prefronto-pontine tract was found to be severely 


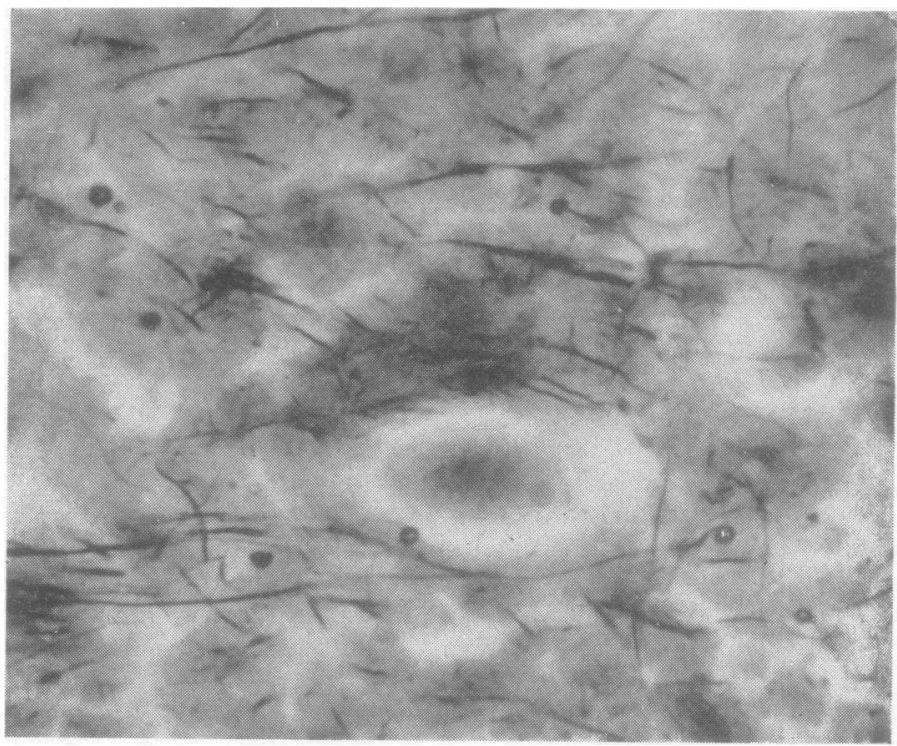

FIG. 6.-Numerous degenerated terminals (Case 1) in the dorso-medial nucleus of the thalamus. $\times 800$.

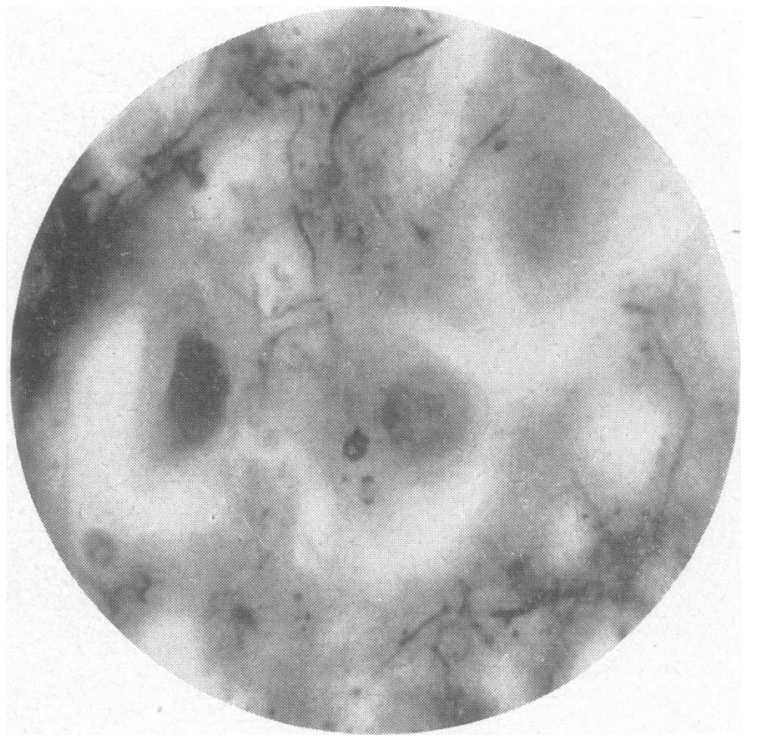

FIG. 7.-Two degenerated terminals (Case 2) on a nerve cell in the ventromedial hypothalamic nucleus; the pericellular plexus has disappeared. $\times 1200$.

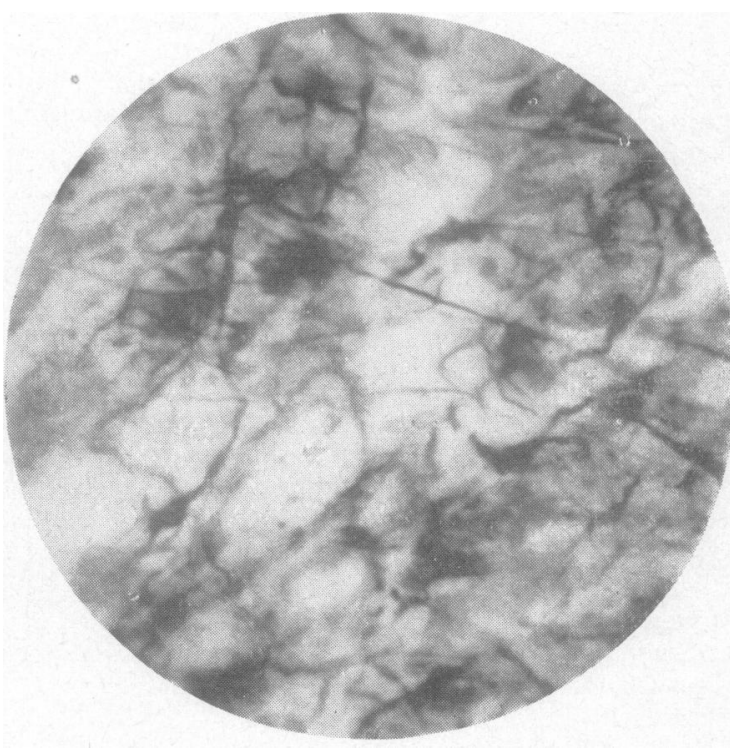

Fig. 8.-Severely degenerated fibres (Case 2) in the medial mammillary nucleus. $\times 1200$.

All photomicrographs are taken from sections treated by the Glees' silver impregnation method. 


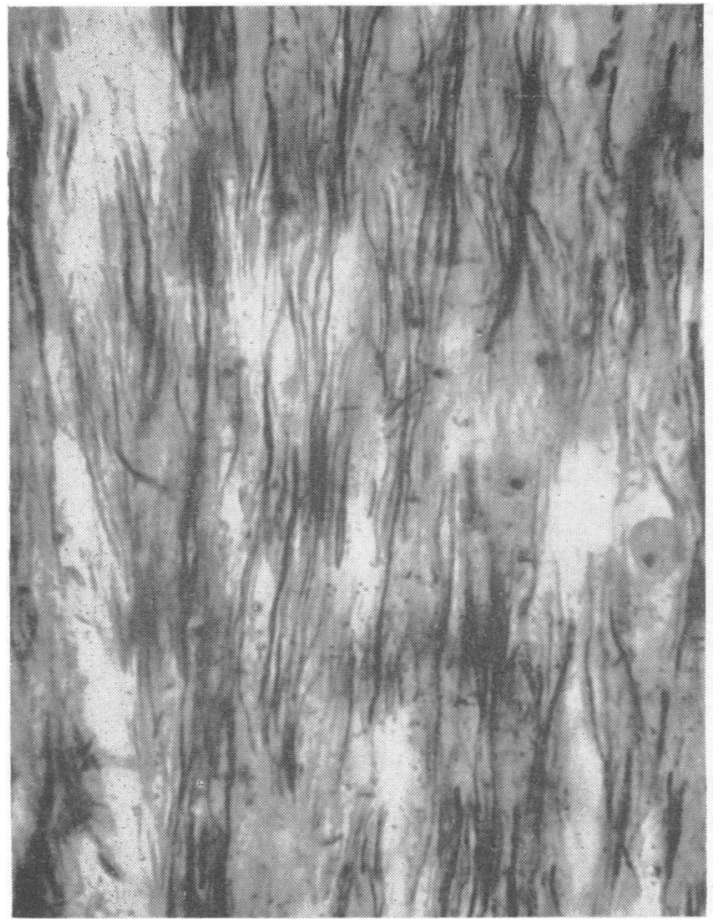

FIG. 9.-Normal appearance of the fine-fibred (Case 1) prefrontopontine fascicles; peduncular level. $\times 1000$.

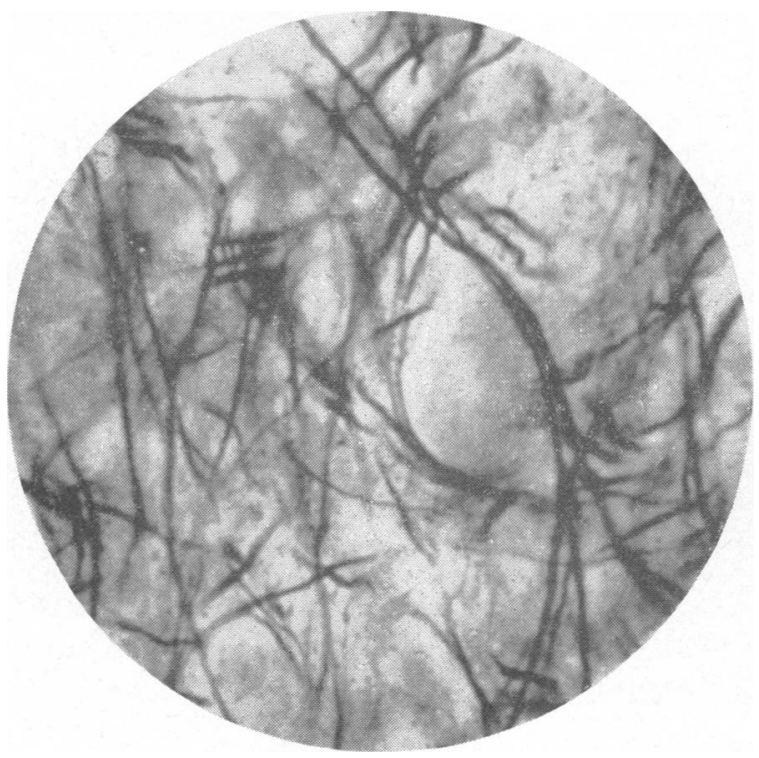

FIG. 11.-Normal fibre plexus (Case 1) around a pontine nerve cell in the immediate vicinity of the small medial fascicles. $\times 1300$.

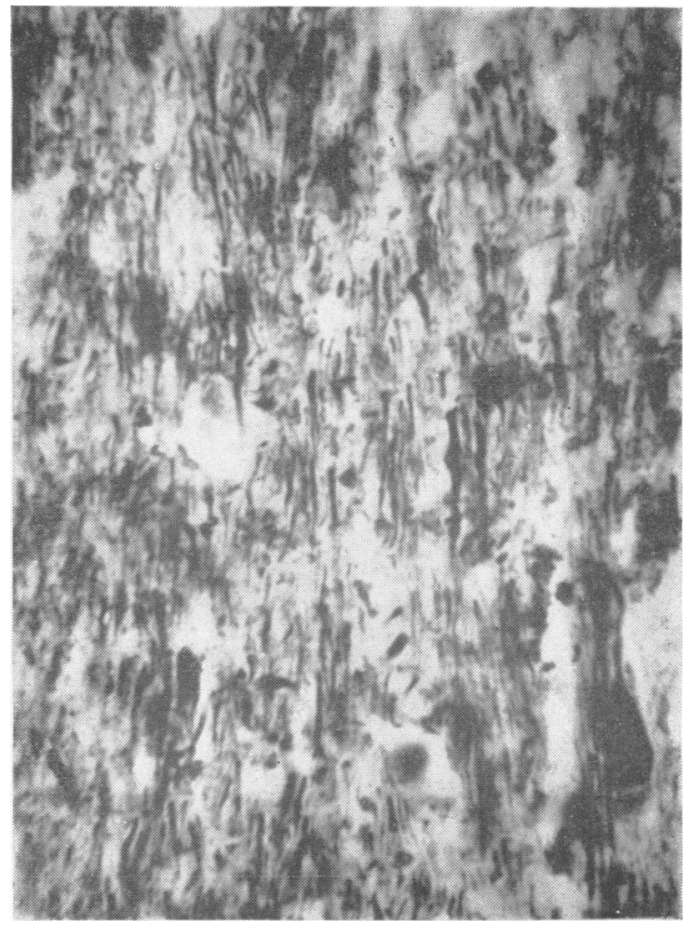

Fig. 10.-The same level in Case 2 as Fig. 9. The fascicles are it completely degenerated, the fibres broken up and irregularly swollen. $\times 1000$.

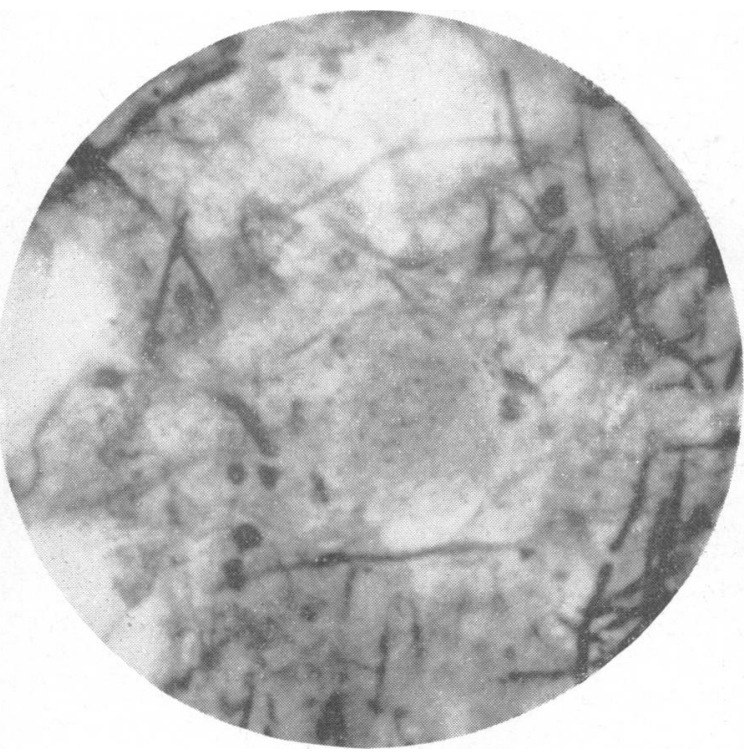

Fig. 12.-The same position (Case 2) as Fig. 11. Numerous degenerated terminals surrounding a pontine nerve cell. The fibre pattern is completely destroyed. $\times 1300$. 
degenerated, with its fascicles completely broken up both within the internal capsule adjacent to the nucleus ventralis lateralis and at the point where they descend into the cerebral peduncle. In the pons many degenerated terminals were seen surrounding the nerve cells in the immediate vicinity of small medial fascicles (Figs. 10 and 12). The ponto-cerebellar fibres were intact.*

The frontal cortex immediately posterior to the lesion showed degeneration in its dorsal and ventral aspects ; laterally it appeared normal. Compared with Case 1 the degeneration was only slight, its distribution within the cortical layers similar.

There was no degeneration in the septal nuclei, the subthalamic nucleus, zona incerta, or Forel's fields $\mathrm{H} 1$ and $\mathrm{H} 2$.

The fasciculus cinguli and the superior longitudinal and uncinate fasciculi were degenerated; a detailed investigation of the long association tracts in this case will be included in a later publication.

Routine blocks showed early senile changes, including slight increase of lipofuscin and a few senile plaques. Only in the region of the hippocampus were these changes more pronounced and accompanied by Alzheimer's neurofibrillar change. We are satisfied that these slight senile changes did not obscure the effects of the leucotomy lesion.

\section{Discussion}

Perhaps the most interesting result of this investigation is the demonstration in the human brain of direct efferent fronto-hypothalamic pathways, arising well in front of the agranular frontal cortex, but not in the region of the frontal pole. The evidence seems to be strong. In Case 1 , with its well defined topectomy of area $10 / \mathrm{FE}$, all the hypothalamic nuclei, which were investigated in great detail, were free of terminal degeneration. On the other hand, in Case 2 where, in addition to the pole, adjacent parts of the orbital surface and dorsal convexity were involved, marked terminal degeneration occurred in the ventromedial and lateral hypothalamic nuclei, and to a lesser degree in the dorso-medial hypothalamic nucleus and the medial mammillary nucleus. Whether the hypothalamic degeneration was caused by the lesion of the medial orbital cortex (areas recta anterior and 11 ), or by the involvement of the cortex on the dorsal convexity, areas $9 / \mathrm{FDm}$ and anterior $8 / \mathrm{FC}$, or by both combined cannot be ascertained from the present material.

There has been only one previous anatomical report describing direct fronto-hypothalamic connexions in the human brain, that of $M$. Meyer (1949) who, working in this department, demon-

\footnotetext{
* While this paper was being written similar degeneration in the hypothalamus and in the prefronto-pontine tract has been confirmed hypothalamus and in the prefronto-pontine tract has been confirmed
in a second case of rostral leucotomy, with an almost identical primary lesion.
}

strated terminal degeneration in the mammillary body in leucotomized brains in which area 6/FB (and possibly anterior parts of 4/FA) were involved. More experience has been gained from experimental work in macaques. Ward and McCulloch (1947), by means of strychnine oscillography, "fired" the mammillary body and the lateral and posterior hypothalamic areas by stimulating area $6 \mathrm{a}$; the supraoptic and paraventricular nuclei received impulses from more anterior frontal areas, while the paraventricular nucleus and the posterior hypothalamic area were fired from the medial and posterior orbital cortex. Le Gros Clark and Meyer (1950) have, so far, published only a summary of their frontal ablation experiments.* They state, however, that there is a massive projection from the agranular orbital cortex (mainly area 13) and also from area 6 upon the ventromedial hypothalamic nucleus which is bilateral, the contralateral fibres crossing in the rostrum of the corpus callosum. This agrees well with our human observations in which the ventromedial hypothalamic nucleus was the main site of terminal degeneration. Whether this connexion is bilateral also in the human brain cannot be ascertained from our Case 2 in which the primary surgical lesions in the two frontal lobes were symmetrical. Le Gros Clark and Meyer also noted degeneration in the dorso-medial hypothalamic nucleus, the anterior hypothalamic area, and the periventricular arcuate nucleus. Only the former showed slight terminal degeneration in our material. The lateral hypothalamic area which was severely degenerated in our material is not mentioned by Le Gros Clark and Meyer, who also, like ourselves, failed to find the degeneration in the supraoptic and paraventricular nuclei which was to be expected from the oscillographic results of Ward and McCulloch. Further anatomical investigations both in the human and monkey brain will be required to decide whether these discrepancies in detail are due to species differences, variation in site and extent of the primary lesion, or to accidental factors. In discussing the differences it should be remembered that area 13 and, indeed, the whole of the agranular orbital cortex, is relatively much smaller in man than in the monkey (Beck, 1949).

The orbito-hypothalamic fibres seem to run ventrally and possibly never enter the internal capsule. Degenerated fibres could be traced in our case from the ventromedial and lateral hypothalamic areas as far forward as the level of the anterior commissure. Here they were found in the region of the medial forebrain bundle and diagonal band

* Wall, Glees, and Fulton (1951), in a report published after the completion of this paper also emphasize the importance of the ventromedial hypothalamic nucleus as an end-station of orbital fibres in macaques. 
below the commissure. It was presumably from this region that Sachs, Brendler, and Fulton (1949) observed strychnine spikes after stimulation of the posterior orbital gyrus of the monkey. Further anteriorly their course was somewhat doubtful, but Yakovlev, Hamlin, and Sweet (1950) described in normal myelin preparations fine fibres which they were able to follow from the "orbital limbus" through the putamino-caudate junction ventral to the anterior commissure into, among other regions, the lateral hypothalamic area. These fibres might be identical with those observed degenerated in the same region in our Case 2.

The existence of direct fronto-hypothalamic pathways is of considerable interest in view of the role which the posterior orbital cortex and the premotor region have been assumed to play in autonomic control. Delgado and Livingston (1948) showed that in monkeys and dogs stimulation of Walker's area 13 resulted in changes of respiration and blood pressure ; Livingston, Fulton, Delgado, Sachs, Brendler, and Davis (1948) extended these investigations to other autonomic functions, while Livingston, Chapman, Livingston, and Kraintz (1948) obtained a similar effect in the human brain stimulated before leucotomy. However, more recent observations have thrown some doubt on assigning considerable autonomic function to the orbital region in the human brain. Scoville (1949), and Scoville and his associates (1951) found neither autonomic disturbances nor the stereotyped restlessness, previously described by Ruch and Shenkin (1943), after very complete undercutting of the orbital cortex. Scoville's findings tally with observations made by one of us (Le Beau, unpublished) even after complete ablation of at least the medial two-thirds of the orbital cortex. Penfield and Rasmussen (1950) have likewise adopted a more critical attitude towards a major participation of the human cerebral cortex in controlling autonomic function. This aspect of the problem therefore also calls for further investigation.

The fronto-thalamic connexions will not be discussed here in detail. The subject has been dealt with exhaustively by Meyer (1949), and the findings in our second case are in complete agreement with her description. According to her classification this case would rank together with her Cases 3 and 4 as a purely " prefrontal " case, i.e., degeneration in the dorso-medial thalamic nucleus was slight and none of the other thalamic nuclei were affected. In our Case 1 the degeneration in the dorsomedial nucleus, although circumscribed and confined to a small focus in its antero-medial part was severe. Positive findings in this case, which was complicated by a vascular lesion, carry less weight than negative ones ; it is, however, at least possible to argue that in a case of ablation more fibres are involved than in leucotomy, particularly if one assumes that they may remain for some distance within the subcortical white matter before they converge in the centrum ovale. The integrity of the subcortical fibres has often been observed in our leucotomy material and has also been convincingly demonstrated by Sweet, Cotzias, Seed, and Yakc vlev (1948). It thus seems possible that the prefronto-dorsomedial connexion is not as insignificant in the human brain as was deduced by Meyer (1949). These considerations equally apply to the short association fibres which were substantially degenerated in Case 1 and only negligibly affected in Case 2.

The remaining findings require only brief comment. Case 1 provides an elegant confirmation of the conclusion come to by one of us (Beck, 1950) that area 10/FE does not contribute to the prefrontopontine tract.

Of the long association tracts only the superior longitudinal fasciculus showed mild degeneration. Degeneration of this system as well as of the fasciculus cinguli and the uncinate fasciculus has been described after prefrontal leucotomy in previous publications from this laboratory (Meyer and his associates, 1947, 1948). Recently the importance of their involvement has been stressed by Gruenthal (1950), Hassler (1950), and Yakovlev and others (1950), but so far this is not borne out in our material (Meyer and McLardy, 1948).

The septal nuclei were completely normal; connexions from various frontal areas to these nuclei as described by Mettler (1947) and von Bonin and Green (1949) could not be confirmed.

\section{Summary}

Efferent connexions of the frontal pole have been studied by the Glees silver impregnation method in a case of topectomy of area 10/FE. The findings have been contrasted with a case of rostral leucotomy, aimed at undercutting areas $9 / \mathrm{FDm}$ and 10/FE.

Efferent fibre systems arising from the extreme frontal pole are very few. They are confined to a distinct projection upon the dorso-medial thalamic nucleus, some short association fibres to adjacent prefrontal cortex, a few callosal fibres, and a weak contribution to the superior longitudinal fasciculus. There is no connexion with the hypothalamus or any other subcortical centres.

A direct cortico-hypothalamic pathway has been demonstrated originating anterior to the agranular frontal cortex and terminating in the ventro-medial and lateral hypothalamic nuclei. Whether this tract arises from the medial orbital or dorsal frontal 
cortex cannot be determined from the present material.

We are indebted to Dr. D. N. Parfitt who made available to us the pathological material and clinical data of Case 2, and to Miss Margaret Simms for technical assistance.

\section{REFERENCES}

Beck, E. (1949). J. Anat., Lond., 83, 147. (1950). Brain, 73, 368.

Bonin, G. von, and Green, J. R. (1949). J. comp. Neurol., 90, 243.

Clark, W. E. Le Gros, and Meyer, M. (1947). Brain, 70, 304. 1536).

Delgado; J. M. R., and Livingston, R. B. (1948). J. Neurophysiol., 11, 39.

Freeman, W., and Watts, J. W. (1947). J. comp. Neurol., 86,65 .

Glees, P. (1946). J. Neuropath. exp. Neurol., 5, 54.

Gruenthal, E. (1950). Mschr. Psychiat. Neurol., 119, 361. Hassler, R. (1950). Fortschr. Neurol. Psychiat., 18, 351.

Livingston, R. B., Chapman, W. P., Livingston, K. E., and Kraintz, L. (1948). Res. Publ. Ass. Res. nerv. ment. Dis., 27, 421.

, Fulton, J. F., Delgado, J. M. R., Sachs, E., Brendler, S. J., and Davis, G. D. (1948). Ibid., 27, 405.
McLardy, T. (1950). Journal of Neurology, Neurosurgery and Psychiatry, 13, 198.

Mettler, F. A. (1947). J. comp. Neurol., 86, 119.

Meyer, A., Beck, E., and McLardy, T. (1947). Brain, 70, 18.

-, and McLardy, T. (1948). J. ment. Sci., 94, 555. ,$- \ldots$, and Beck, E. (1948). Folia psychiat. neurol. neurochir. neerl. Congresnummer, 51, 45.

Meyer, M. (1949). Brain, 72, 265.

Nauta, W.J.H. (1950). Schweiz. Arch. Neurol.Psychiat., 66, 353.

Penfield, W., and Rasmussen, T. (1950). " The cerebral cortex of man," pp. 1-248. New York.

Ruch, T. C., and Shenkin, H. A. (1943). J. Neurophysiol. $6,349$.

Sachs, E., Brendler, S. J., and Fulton, J. F. (1949). Brain, 72, 227.

Scoville, W. B. (1949). J. Neurosurg., 6, 65.

- Wilk, E. K., and Pepe, A. J. (1951). Amer. J. Psychiat., 107, 730 .

Sweet, W. H., Cotzias, G. C., Seed, J., and Yakovlev, P. (1948). Res. Publ. Ass. Res. Nerv. Ment. Dis., 27, 795.

Walker, A. E. (1940a). J. comp. Neurol., 73, 59. (1940b). Ibid., 73, 87.

Wall, P. D., Glees, P., and Fulton, V. F. (1951). Brain, 74, 66.

Ward, A. A., and McCulloch, W. S. (1947). J. Neurophysiol., 10, 309.

Yakovlev, P., Hamlin, H., and Sweet, W. H. (1950). J. Neuropath. exp. Neurol., 9, 250. 